\title{
Extreme ion heating in the dayside ionosphere in response to the arrival of a coronal mass ejection on 12 March 2012
}

\author{
H. Fujiwara ${ }^{1}$, S. Nozawa ${ }^{2}$, Y. Ogawa ${ }^{3}$, R. Kataoka ${ }^{3}$, Y. Miyoshi ${ }^{4}$, H. Jin ${ }^{5}$, and H. Shinagawa ${ }^{5}$ \\ ${ }^{1}$ Faculty of Science and Technology, Seikei University, Tokyo, Japan \\ ${ }^{2}$ Solar-Terrestrial Environment Laboratory, Nagoya University, Nagoya, Japan \\ ${ }^{3}$ National Institute of Polar Research, Tokyo, Japan \\ ${ }^{4}$ Department of Earth and Planetary Sciences, Kyushu University, Fukuoka, Japan \\ ${ }^{5}$ National Institute of Communication Technology, Tokyo, Japan \\ Correspondence to: H. Fujiwara (h_fujiwara@st.seikei.ac.jp)
}

Received: 28 February 2014 - Revised: 9 June 2014 - Accepted: 12 June 2014 - Published: 23 July 2014

\begin{abstract}
Simultaneous measurements of the polar ionosphere with the European Incoherent Scatter (EISCAT) ultra high frequency (UHF) radar at Troms $\varnothing$ and the EISCAT Svalbard radar (ESR) at Longyearbyen were made during 07:00-12:00 UT on 12 March 2012. During the period, the Advanced Composition Explorer (ACE) spacecraft observed changes in the solar wind which were due to the arrival of coronal mass ejection (CME) effects associated with the 10 March M8.4 X-ray event. The solar wind showed two-step variations which caused strong ionospheric heating. First, the arrival of shock structures in the solar wind with enhancements of density and velocity, and a negative interplanetary magnetic field (IMF)- $B_{z}$ component caused strong ionospheric heating around Longyearbyen; the ion temperature at about $300 \mathrm{~km}$ increased from about 1100 to $3400 \mathrm{~K}$ over Longyearbyen while that over Troms $\varnothing$ increased from about 1050 to $1200 \mathrm{~K}$. After the passage of the shock structures, the IMF- $B_{z}$ component showed positive values and the solar wind speed and density also decreased. The second strong ionospheric heating occurred after the IMF- $B_{z}$ component showed negative values again; the negative values lasted for more than $1.5 \mathrm{~h}$. This solar wind variation caused stronger heating of the ionosphere in the lower latitudes than higher latitudes, suggesting expansion of the auroral oval/heating region to the lower latitude region. This study shows an example of the CME-induced dayside ionospheric heating: a short-duration and very large rise in the ion temperature which was closely related to the polar cap size and polar cap potential variations as a result of interaction between the solar wind and the magnetosphere.
\end{abstract}

Keywords. Ionosphere (auroral ionosphere; ionospheric disturbances; polar ionosphere)

\section{Introduction}

Relationships between the solar phenomena and variations of the ionosphere/thermosphere have been one of the most important issues in aeronomy. Although many researchers have investigated variations of the ionosphere/thermosphere during periods of solar wind energy injection into the polar region, complete features of connections between the Sun, solar wind, magnetosphere, ionosphere, and thermosphere are still unknown.

Recently, some satellite observations have quantitatively revealed one-to-one correspondence between the phenomena on the solar surface and the responses of the ionosphere/thermosphere. For example, Thayer et al. (2008) and Lei et al. (2008a, b) reported recurrent geomagnetic activities and variations of the ionosphere/thermosphere caused by changes in the solar wind in association with periodic solar wind high-speed streams coming from rotating solar coronal holes. From the CHAMP (CHAllenging Minisatellite Payload) satellite observations, Lei et al. (2011) also showed variations of the thermosphere density around $400 \mathrm{~km}$ altitude caused by solar wind high-speed streams/corotating interaction regions (CIRs) during the exceptionally quiet solar minimum of 2008 .

In addition to CIRs, coronal mass ejections (CMEs) are another typical cause of geomagnetic storms. For example, 
Kataoka and Miyoshi (2006) summarized the characteristics of CME-driven and CIR-driven storms. The effects of the CME-induced and CIR-induced geomagnetic activity on the thermosphere density and satellite orbit decays were reported by Chen et al. (2012). They pointed out that the total thermosphere density changes and satellite orbit decays for entire periods of CIR-storms were greater than those for CMEstorms because CME-storms were shorter than CIR storms, although CME-storms were stronger than CIR-storms on average. Since the CIRs/solar wind high-speed streams occur frequently and periodically, details of the thermosphere density variations have been investigated by, e.g., Thayer et al. (2008), Lei et al. (2008a, b, 2011), Sojka et al. (2009), and Gardner et al. (2012) during the declining phase and near the minimum of the solar cycle. However, since CME events are less frequent than CIRs without periodic occurrence, details of responses of the ionosphere and thermosphere to the CME-induced geomagnetic activity are relatively unknown. Since CME-storms are stronger than CIR-storms (Kataoka and Miyoshi, 2006; Richardson et al., 2006; Denton et al., 2006; Chen et al., 2012), large amplitudes of disturbances are expected in the polar ionosphere/thermosphere.

As mentioned above, the CHAMP satellite made great contributions to understanding of the thermosphere density variations. In particular, the thermosphere density was found to be enhanced in the vicinity of the cusp region (e.g., Lühr et al., 2004; Liu et al., 2005), and Carlson et al. (2012) investigated the physical mechanisms for driving the disturbances of the ionosphere/thermosphere in the cusp/polar cap region. Based on the CHAMP observations, many researchers focused on the thermosphere density variations, while complete pictures of the energetics and dynamics of the ionosphere/thermosphere in the cusp/polar cap region are not shown yet. Although we pointed out the importance of heat sources in the cusp/polar cap region in our previous studies (Fujiwara et al., 2007, 2012), there has not been enough observation of temperature and wind in the region. In order to investigate the energetics in the ionosphere/thermosphere in the cusp/polar cap region, simultaneous measurements of the polar ionosphere with the EISCAT ultra high frequency (UHF) radar at Troms $\varnothing$ and the EISCAT Svalbard radar (ESR) at Longyearbyen were made during 07:00-12:00 UT on 12 March 2012. During the period, we successfully observed variations of the ionosphere due to prominent changes in the solar wind which was caused by arrival of CME effects associated with the M8.4 solar flare event on 10 March 2012. In this study, we show an example of the ion temperature variations due to the CME-induced geomagnetic activity.

\section{Solar activity and geophysical condition}

The solar activity was increasing in 2012 towards a maximum. The solar flare and CME events were observed successively during 5-14 March 2012. On 12 March we observed

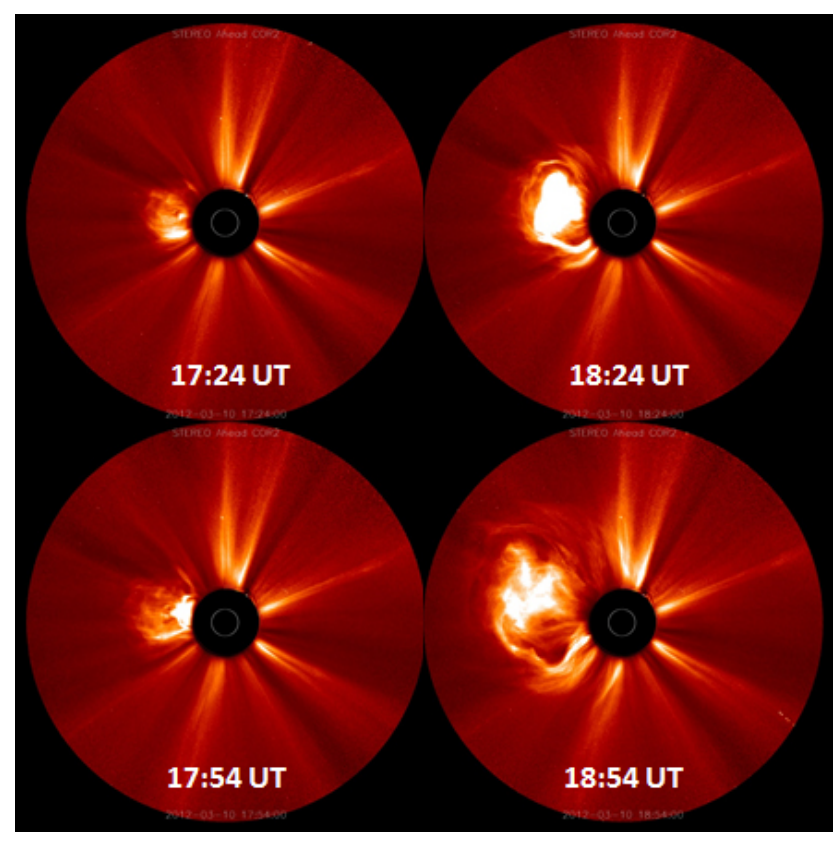

Figure 1. Solar images obtained from the STEREO Ahead COR2 observations at 17:24, 17:54, 18:24, and 18:54 UT on 10 March 2012.

the ionospheric variations which were caused by one of the CMEs on 10 March. The daily value of the F10.7 index was 115 solar flux units (sfu) on 12 March, which is the same value of the monthly average.

On 12 March, interplanetary shock was observed at 08:40 UT by the Advanced Composition Explorer (ACE) spacecraft. The following large changes in the solar wind were caused by the arrival of a CME associated with the M8.4 solar flare event at 17:27 UT on 10 March as originated from Region 1429. In association with the M8.4 flare, a bright CME occurred and was Earth directed. Figure 1 shows examples of the solar image during the CME event obtained from the STEREO (Solar TErrestrial RElations Observatory) Ahead outer coronagraph (COR2) observations.

Figure 2 shows solar wind variations observed by the ACE spacecraft (level 2 data) during our observational period: the interplanetary magnetic field (IMF) $B_{x}, B_{y}, B_{z}$ components, solar wind density (particles $/ \mathrm{cc}=\mathrm{cm}^{-3}$ ), solar wind speed from the top to bottom panels, respectively. The polar ionosphere was heated 40-60 min after the passage of the peculiar solar wind structures at the ACE position. At around 08:40 UT, the ACE spacecraft observed shock structures in the solar wind as identified with rapid increases of the solar wind speed and density from about 420 to $580 \mathrm{~km} \mathrm{~s}^{-1}$ and from about 5 to 70 particles/cc, respectively. The IMF$B_{z}$ component also showed large negative values $(\sim-20 \mathrm{nT})$ at that time. After the passage of the shock structures, the IMF- $B_{z}$ component showed positive values. The solar wind speed and density also decreased. At around 10:10 UT, the 

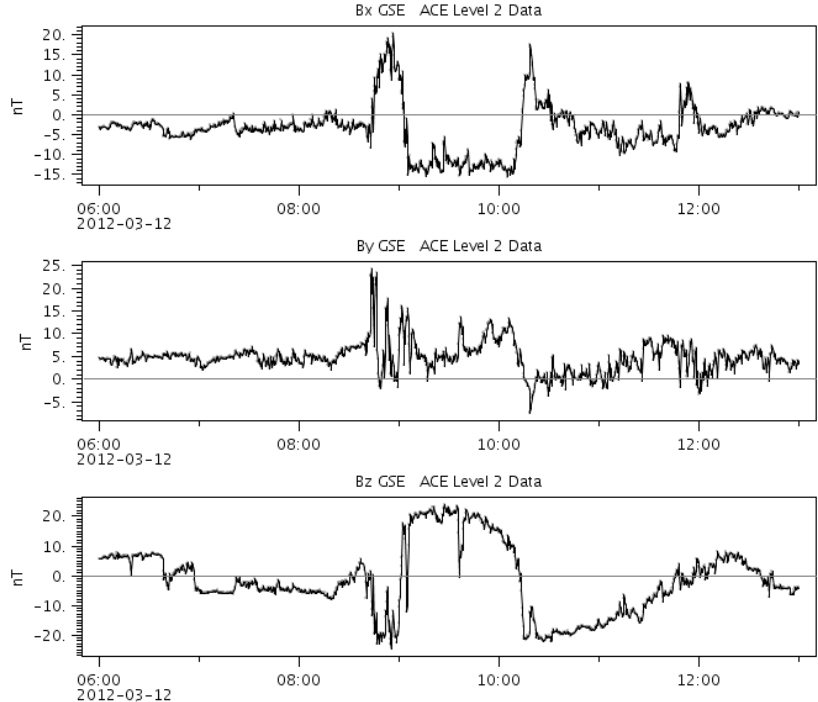

Proton Number density ACE Level 2 Data
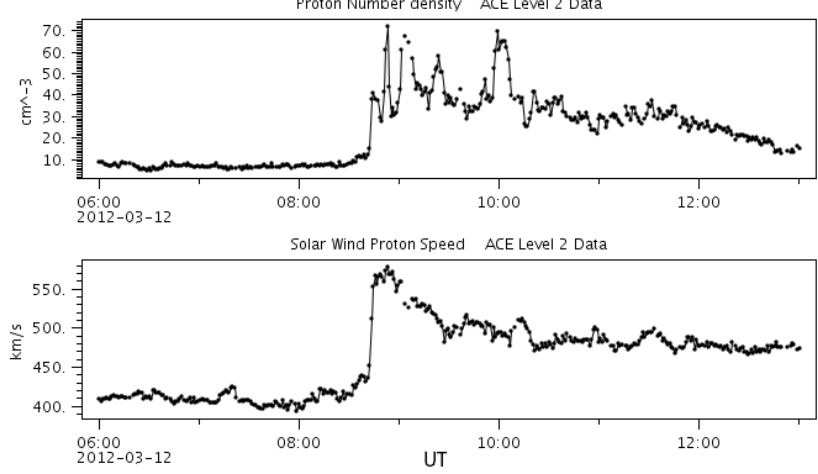

Figure 2. Solar wind variations during 06:00-13:00 UT on 12 March 2012 observed by the ACE spacecraft. IMF- $B_{x}, B_{y}, B_{z}$ components, density, and speed are shown from the top to bottom panels, respectively.

IMF- $B_{z}$ component showed negative values again and the negative values lasted until about 12:00 UT. The solar wind speed and density fluctuated around $470-520 \mathrm{~km} \mathrm{~s}^{-1}$ and 20-40 particles/cc, respectively, until about 12:00 UT except for a sudden excursion of the density $(\sim 70$ particles/cc $)$ at around 10:00 UT.

In summary, this is a kind of usual CME-induced shock downstream events, with moderate solar wind speed and somewhat large solar wind density. In fact, there are a number of similar but stronger CME-induced shock downstream events (solar wind speed Vsw $>600 \mathrm{~km} \mathrm{~s}^{-1}$ and $|B|>20 \mathrm{nT}$ ) as documented by Kataoka et al. (2005).

The Boyle index (Boyle et al., 1997), which is an asymptotic polar cap potential, is calculated from the solar wind parameters. The upper panel in Fig. 3 shows time series of the Boyle index provided from Rice Space Institute/Rice University (http://mms.rice.edu/realtime/forecast.html). Large enhancements are seen at around 09:00 and 11:00 UT in association with the solar wind variation, suggesting the large polar
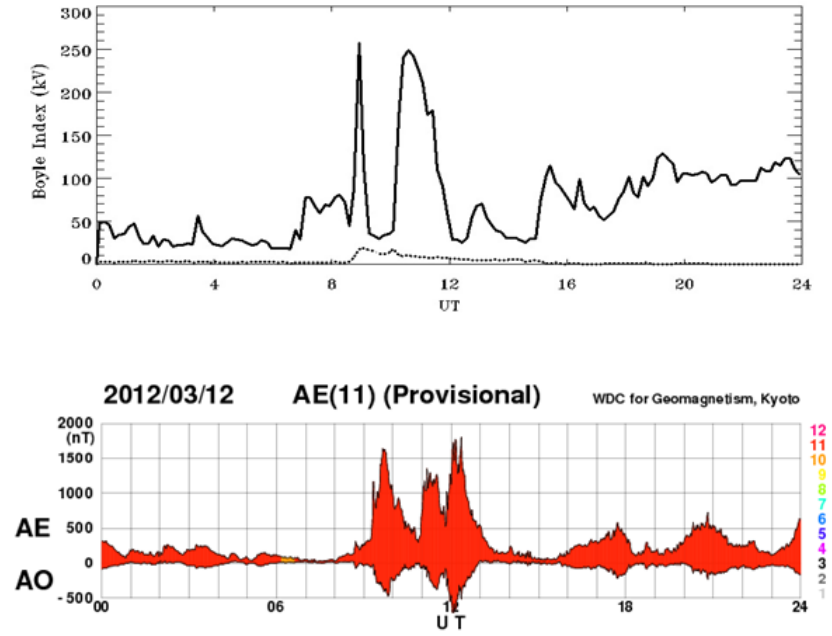

Figure 3. The upper panel indicates the Boyle index, which is an asymptotic polar cap potential (kV), on 12 March 2012 calculated from the solar wind parameters. The solar wind dynamic pressure (in units of $\mathrm{nPa}$ ) is also shown with dotted line in the upper panel. The lower panel indicates the provisional geomagnetic field indices (AE and AO) on 12 March 2012. The number of stations used to derive the indices is shown in color.

cap potential drops after the periods. Note that the Boyle index could be a good predictor of the polar cap potential drop when the solar wind is steady and the index is less than $160 \mathrm{kV}$. The peak values exceeding $160 \mathrm{kV}$ in Fig. 3 could be overestimated. The Boyle index is one of proxies for describing the magnetospheric activity as a result of solar wind variations.

The solar wind-magnetosphere interaction during the period also caused changes in geomagnetic activity. As the effects of the CME continued, periods of major storms were observed with isolated severe storm levels at high latitudes from 09:00-15:00 UT as shown in the provisional AE index (lower panel in Fig. 3).

\section{ESR/EISCAT UHF radar observations}

The European Incoherent Scatter (EISCAT) UHF radar at Troms $\varnothing$ is located at $69.6^{\circ} \mathrm{N}, 19.2^{\circ} \mathrm{E}\left(66.5^{\circ} \mathrm{N}, 103.4^{\circ} \mathrm{E}\right.$ in geomagnetic coordinates). The local solar time (LST) and the magnetic local time (MLT) at Troms $\varnothing$ are approximately $\mathrm{UT}+1$ and $\mathrm{UT}+2.5$, respectively. The EISCAT UHF radar experiment was conducted as a scanning mode where the antenna scanned sequentially five positions with a cycle time of $10 \mathrm{~min}$. The antenna positions of azimuth and elevation are set to be $30^{\circ}, 30^{\circ} ; 0^{\circ}, 30^{\circ} ; 0^{\circ}, 60^{\circ} ; 0^{\circ}, 90^{\circ}$; and $0^{\circ}$, $60^{\circ}$ during a scanning cycle. Hereafter, we call them as beam 1 , beam 2 , beam 3 , beam 4 , and beam 5 , respectively. Note that beams 3 and 5 are identical. The beams $2-5$ were pointed in the same geographic meridian. The antenna is directed to beam 1 position after beam 5 position. By using the 


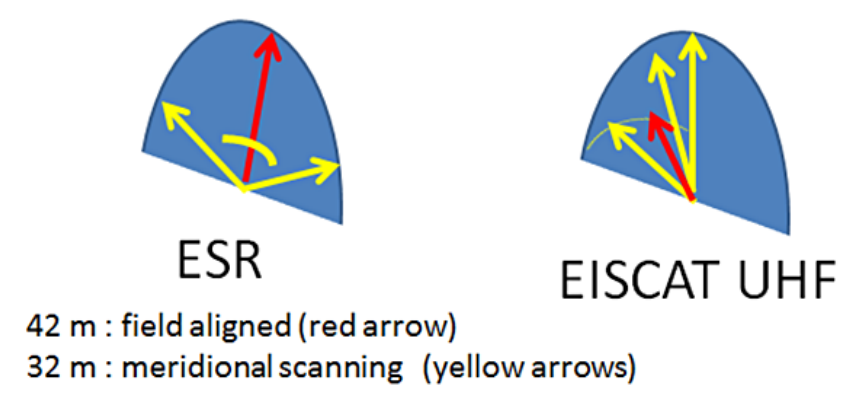

Figure 4. Schematic illustration of the beam directions of the ESR and EISCAT UHF radar employed in the present study. The $42 \mathrm{~m}$ antenna of the ESR was pointed in the field-aligned direction (red arrow in the left panel), while the $32 \mathrm{~m}$ antenna of the ESR was run in the geomagnetic meridional plane (yellow arrows in the left panel). The EISCAT UHF radar pointed in the direction of the geographic meridional plane (yellow arrows in the right panel) and had a beam departing $30^{\circ}$ azimuthally from the meridional plane (red arrow in the right panel).

line-of-sight ion velocity data obtained from beam 1 , beam 2 , and beam 4 observations, we derive the ion velocity vector and then the electric field with the assumption of the spatial homogeneity of the beam areas as well as the temporal stability for the necessary time for scanning the three positions (i.e., $8 \mathrm{~min}$ ). The EISCAT UHF radar observations were made during 07:00-13:00 UT on 12 March 2012.

The EISCAT Svalbard radar (ESR) at Longyearbyen is located at $78.2^{\circ} \mathrm{N}, 16.0^{\circ} \mathrm{E}\left(75.1^{\circ} \mathrm{N}, 113.0^{\circ} \mathrm{E}\right.$ in geomagnetic coordinates). The LST and MLT at Longyearbyen are approximately UT +1 and UT +3 , respectively. Since we had limitations for the ESR operation because of a system problem during the period, the ESR experiment was conducted in so-called CP3 mode with the $32 \mathrm{~m}$ antenna (magnetic meridian scanning with 15 beams with a time of $6 \mathrm{~s}$ in each beam) and field aligned direction observations were made with the $42 \mathrm{~m}$ antenna. The ESR observations were made during 07:00-12:00 UT. Figure 4 shows a schematic illustration of the beam directions of the ESR and the EISCAT UHF radar employed in our observations.

Figure 5 shows temporal variations of the electron density, electron temperature, ion temperature, and ion line-of-sight velocity (the ion motion away from the observation site is positive) from the top to the bottom, respectively. The left and right panels indicate values obtained from the ESR observations with the $42 \mathrm{~m}$ antenna (in the altitude range of 90 $800 \mathrm{~km}$ ) and the EISCAT UHF radar observations (in the altitude range of $90-600 \mathrm{~km}$ ), respectively. Note that the results of all the beam directions are plotted every two minutes in the right panel. The ion temperature enhancements start at around 09:00 UT in the ESR observations, while variations are not so significant in other parameters and the EISCAT UHF radar observations at around 09:00 UT. During about 09:15-09:40 UT, large enhancements of the ion temperature are seen in the ESR observations. Changes in the electron density, electron temperature (particularly in the lower altitude region $(100-300 \mathrm{~km})$ ), and ion velocity (large negative values above about $200 \mathrm{~km}$ ) are also found in the ESR observations. Although enhancements of the ion temperature and ion velocity are also seen in the EISCAT UHF observations, the values in the EISCAT UHF observations are smaller than those in the ESR observations during the period, except for some of the ion velocity. The enhancements in the EISCAT UHF radar observations seem to occur slightly later than those in the ESR observations. During about 10:0011:00 UT, the ionospheric parameters obtained from the ESR observations show quasi-periodic variations although the approximate periods seem to be different between the parameters; the ion temperature seems to vary with a period of about $30 \mathrm{~min}$ (about $200-450 \mathrm{~km}$ altitude) while the electron temperature and ion velocity seem to vary with periods less than $10 \mathrm{~min}$ (about 300-450 km altitude). On the other hand, the EISCAT UHF radar did not observe significant changes in the ionospheric parameters during 10:00-11:00 UT. After 11:00 UT, the ionospheric parameters obtained from the EISCAT UHF radar observations show quite large variations, particularly seen in the ion temperature and velocity. The ESR, however, did not observe significant ionospheric variations compared to the EISCAT UHF radar observations after 11:00 UT although there are data gaps during about 11:2011:30 UT.

We made the same observations on 13 March. The values of indices F10.7 and Kp were $141 \mathrm{sfu}$ and $1+\sim 2$, respectively, during the observational period on 13 March. The ionospheric parameters on 13 March obtained from the ESR and the EISCAT UHF radar are shown in Fig. 6 as a reference of the relatively quiet day. Although there are some data gaps because of the radar system problems, we can see the relatively quiet ionosphere with small variations. For example, the ion temperature at about $300 \mathrm{~km}$ obtained from the ESR and the EISCAT UHF radar varied from about 1000-1500 K except for some enhancements of about $2000 \mathrm{~K}$.

Figure 7 shows the ion temperature variations at about $300 \mathrm{~km}$ altitude on 12 March. The black line indicates the ion temperature observed with the ESR $42 \mathrm{~m}$ at Longyearbyen (hereafter we call this ion temperature as Ti-1). The red, blue, and green lines show the ion temperatures obtained from the EISCAT UHF radar observations at Troms $\varnothing$ with beam 2 , beam 3 , and beam 4 , respectively (hereafter we call these ion temperatures as Ti-2, Ti-3, and Ti-4). The red dotted line shows the ion temperature obtained from the EISCAT UHF radar observations at Troms $\varnothing$ with beam 1 (hereafter we call this ion temperature as Ti-5). The ion temperature enhancements at around 09:00 UT and during about 09:1509:40 UT are clearly seen in the ESR observations (Ti-1). The ion temperature (Ti-1) changes from about $1100 \mathrm{~K}$ (before the enhancement) to $3400 \mathrm{~K}$ (the maximum value), while the ion temperature over Troms $\emptyset$ (Ti-4) changes from about 1050 to $1200 \mathrm{~K}$. Before about 11:00 UT, disturbances of the 

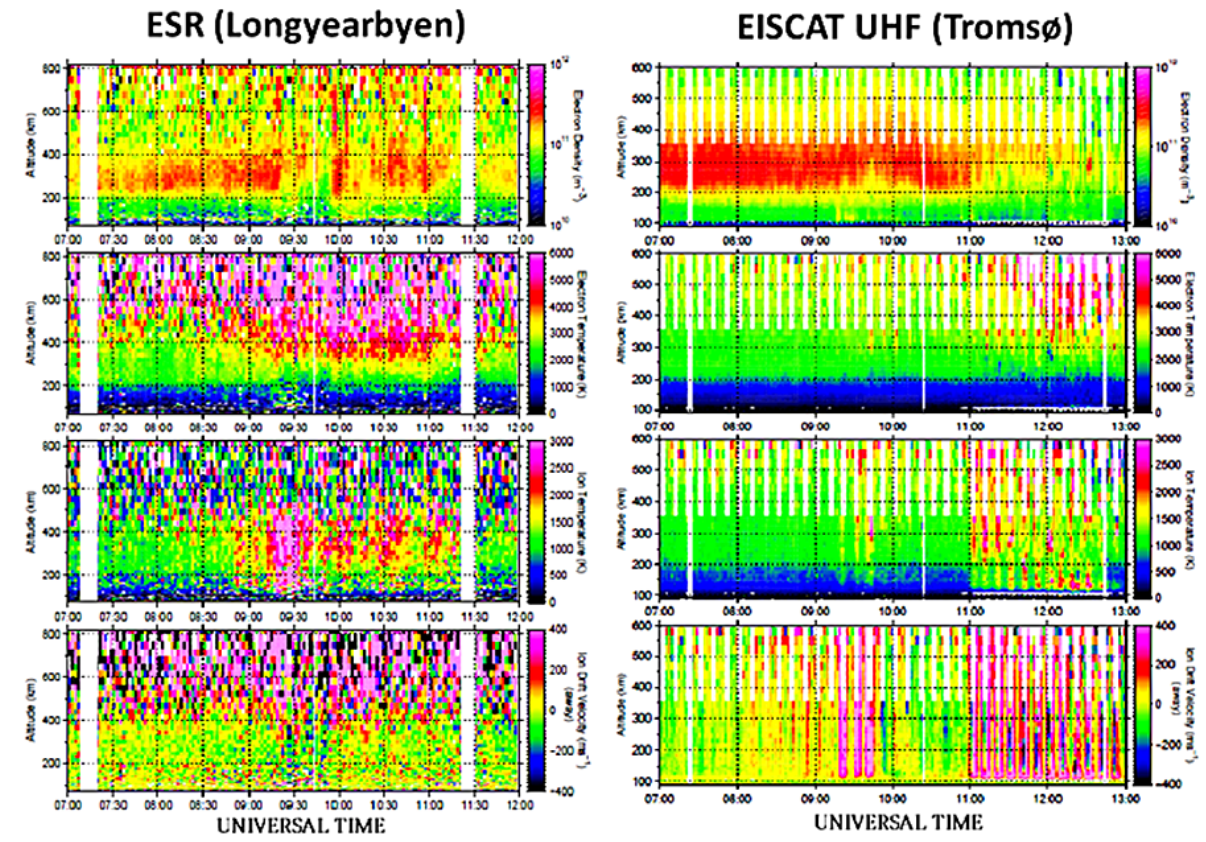

Figure 5. Ionospheric variations in the altitude range of $90-800 \mathrm{~km}$ observed with the EISCAT Svalbard $42 \mathrm{~m}$ radar (ESR) at Longyearbyen (left) and those in the altitude range of 90-600 km observed with the EISCAT UHF radar at Troms $\varnothing$ (right) on 12 March. The electron density, electron temperature, ion temperature, and ion drift velocity are shown from the top to bottom, respectively, in each panel.

ion temperature were generated at higher latitudes; namely, variations of Ti-1 were significant during the period. After about 11:00 UT, the heating regions seem to move to lower latitudes; in particular, enhancements of Ti- 2 and Ti- 5 are remarkable. The maximum value of Ti-5 is about $3800 \mathrm{~K}$ at around 12:00 UT.

The electric field is obtained from the EISCAT UHF radar ion drift observations at $282 \mathrm{~km}$ altitude with beam 1 , beam 2 , and beam 4 . Figure 8 shows the electric field variations on March 12 for geographically northward (blue line) and eastward (red line) components. At around 09:30 UT, small enhancements are seen in the eastward component. At around 11:10 and 12:00 UT, large enhancements are seen in the northward component. The values of the northward component of the electric field at around 11:10 and 12:00 UT are about 85 and $126 \mathrm{mV} \mathrm{m}^{-1}$, respectively. These variations are almost consistent with those of the ion temperature (Ti-2, Ti3 , Ti-4, and Ti-5). In particular, the electric field variations after 11:00 UT are well in agreement with Ti-5.

Figure 9 shows ESR observations on 12 March with the $32 \mathrm{~m}$ antenna which scanned geomagnetic meridional directions. The left panel indicates ionospheric variations observed from the northward-directed beam with elevation angles $32-52^{\circ}$. The right panel is the same as the left one except for the southward-directed beam. Note that the ion drift direction away from the observation site is positive; namely, the poleward ion motion is positive and negative in the left and right panels, respectively. The ion temperature in the altitude range of about $120-300 \mathrm{~km}$ is much larger in the northern direction (left panel) than that in the southern direction (right panel) before about 09:30 UT.

The northward observation data (left panel in Fig. 9) show enhancements of the ion temperature in the altitude range of about $120-250 \mathrm{~km}$ at 09:18 UT. After that, large enhancements of the ion temperature (>3000 K) above about $100 \mathrm{~km}$ altitude are seen at 09:28 UT. The large equatorward ion motion (negative values) above about $150 \mathrm{~km}$ altitude is also seen at 09:28 UT. The poleward and equatorward ion motions are seen alternately until 12:00 UT. The enhancements of the ion temperature seem to have occurred during the equatorward ion motion. The southward observation data (right panel in Fig. 9) shows enhancements of the ion temperature (>3000 K) above about $100 \mathrm{~km}$ altitude just after 09:30 UT. At that time, strong poleward ion motion (negative values) is seen. The ion temperature decreased to about $1000-2000 \mathrm{~K}$ during about 10:00-11:00 UT. The ion temperature increased again at around 11:00-11:20 UT. After about 11:30 UT, the ion temperature gradually decreased again. The variations of the ion temperature and motion are almost consistent with the northward observations with the EISCAT UHF radar (in particular, beam 2) at Tromsø.

\section{Summary and discussion}

Simultaneous measurements of the polar ionosphere with the EISCAT UHF radar at Troms $\varnothing$ and the EISCAT Svalbard radar (ESR) at Longyearbyen were made during 07:00-12:00 UT on 12 March 2012. During the period, we 

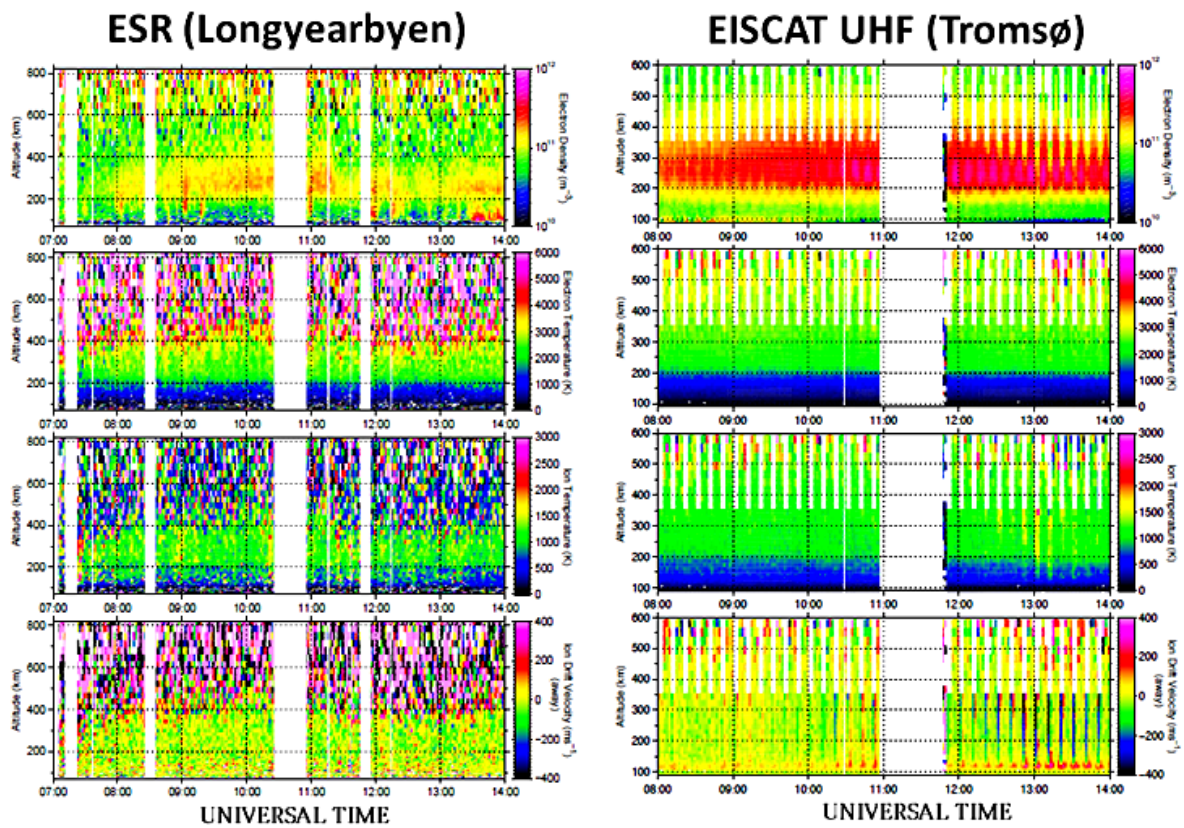

Figure 6. Same as Fig. 5 except for 13 March; observations on the relatively quiet day.

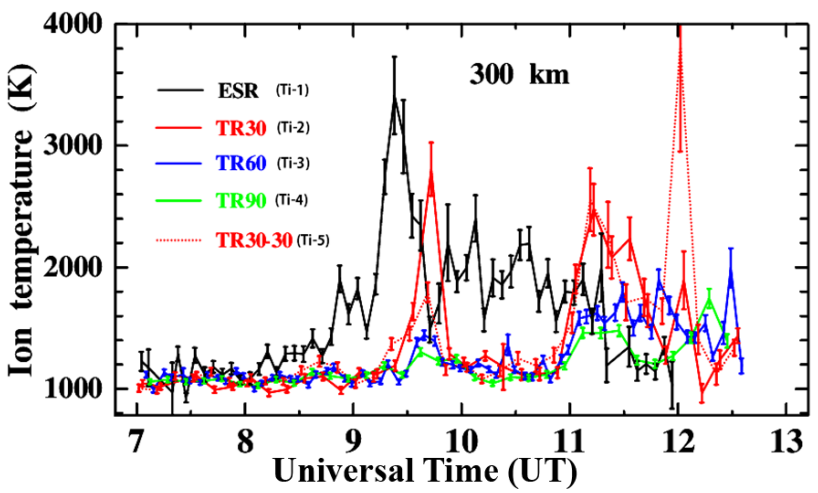

Figure 7. Ion temperature variations at about $300 \mathrm{~km}$ altitude on 12 March. The black line indicates the ion temperature observed with ESR $42 \mathrm{~m}$ at Longyearbyen. The red, blue, and green lines show the ion temperatures derived from the EISCAT UHF radar observations at Troms $\varnothing$ with beam 2 , beam 3 , and beam 4 , respectively. The red dotted line shows the ion temperature derived from the EISCAT UHF observations at Troms $\emptyset$ with beam 1.

successfully observed variations of the polar ionosphere due to shock downstream structure of the solar wind which was caused by the arrival of a CME associated with the M8.4 solar flare event on 10 March. The characteristics of the changes in the solar wind were (1) passage of interplanetary shock structures, e.g., sudden excursions of the solar wind speed (from $\sim 420$ to $\sim 580 \mathrm{~km} \mathrm{~s}^{-1}$ ) and density (from $\sim 10$ to $\sim 40$ particles/cc on average), and short-duration southward turning of the IMF- $B_{z}$ component and (2) southward IMF- $B_{z}$ component lasting more than $1.5 \mathrm{~h}$ after the passage of the interplanetary shock.

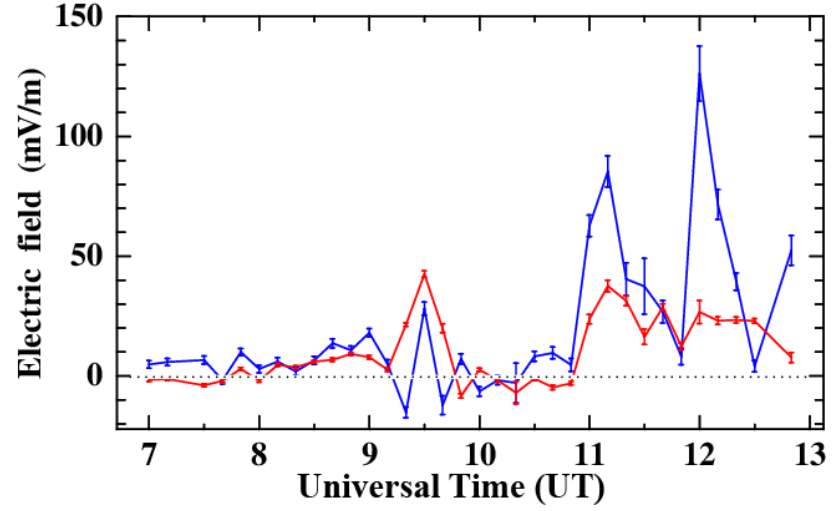

Figure 8. Electric field variations obtained from the EISCAT UHF radar ion drift observations at $282 \mathrm{~km}$ altitude with beam 1 , beam 2 , and beam 4 on 12 March. The geographically northward and eastward components are shown with blue and red lines, respectively.

Before the arrival of the interplanetary shock, the ion temperature at the higher latitude (see the left panel in Fig. 9) in the polar cap region is much larger (by more than $1000 \mathrm{~K}$ ) than that at the lower latitude (see the right panel in Fig. 9). Some previous studies reported high ion temperature and/or large heating rate in the polar cap region (e.g., Fujiwara et al., 2007, 2012). The present observations are consistent with the previous results of the "hot polar cap".

The electric field and ion velocity variations are well in agreement with the ion temperature variations as shown in Figs. 5, 7, 8 and 9. This shows that Joule heating should be the main driver of the ionospheric variations in association 

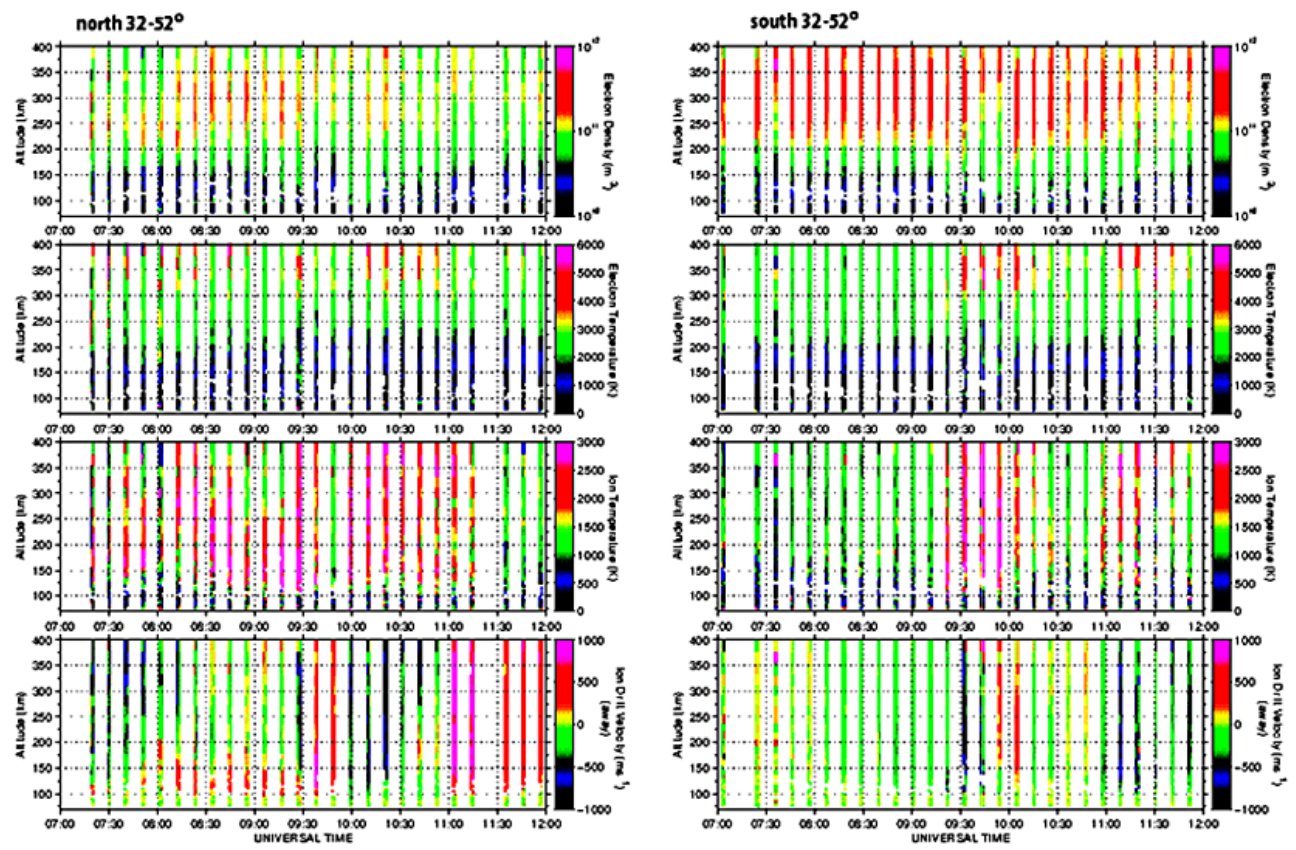

Figure 9. ESR observations with the $32 \mathrm{~m}$ antenna on 12 March. The left panel indicates ionospheric data obtained from the northwarddirected beams with elevation angles $32-52^{\circ}$. The right panel is the same as the left one except for southward-directed beams. Note that the ion drift direction away from the observation site is positive; namely, the poleward ion motion is positive and negative in the left and right panels, respectively.
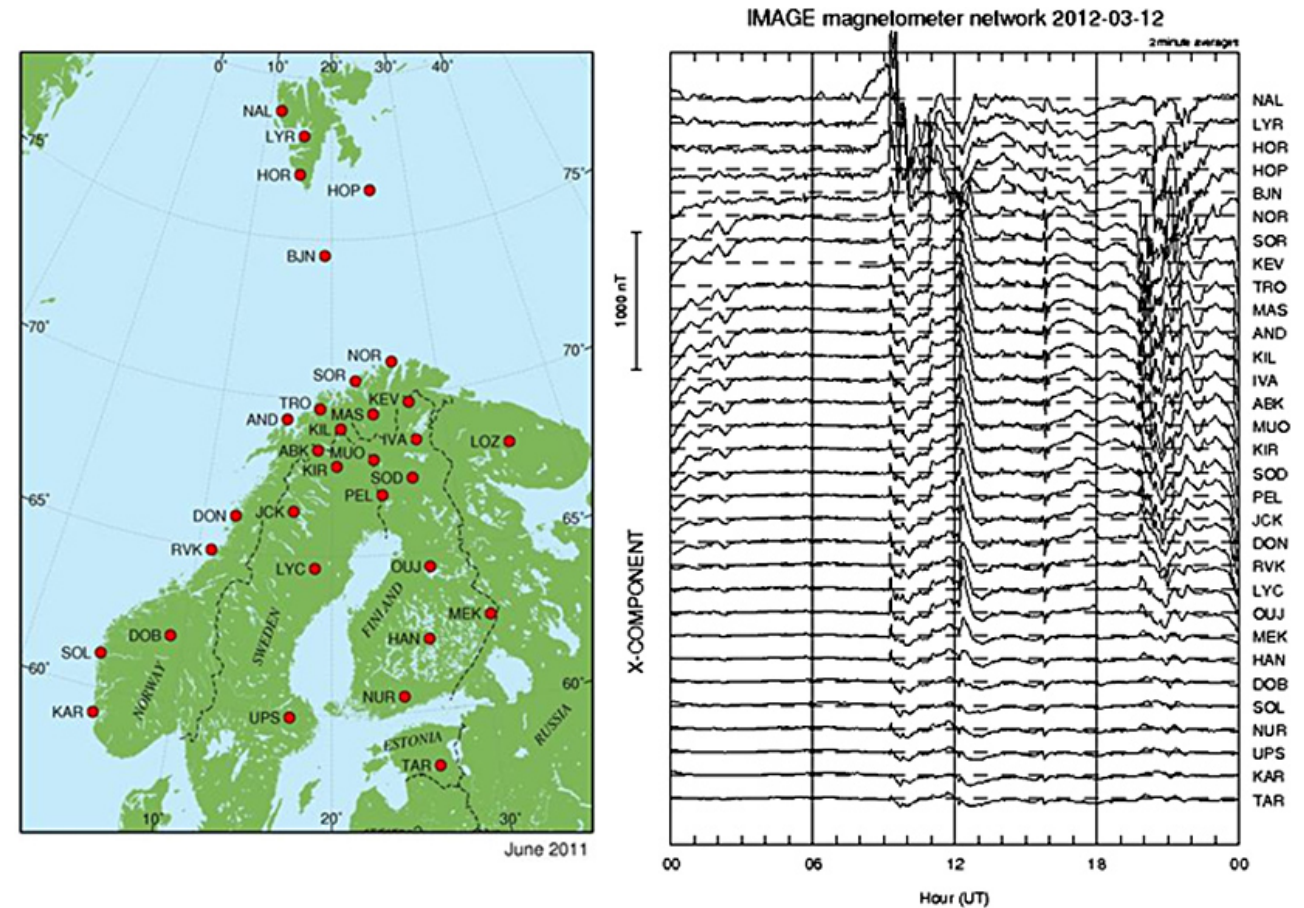

Figure 10. The X-components (northward components) of the geomagnetic field obtained from the IMAGE magnetometer network observations on 12 March 2012 (right panel). The geographic/geomagnetic latitude region from $78.92^{\circ} / 75.25^{\circ}$ (Ny- $\AA$ lesund: NAL) to 58.26 $/ 54.47^{\circ}$ (Tartu: TAR) is covered by the IMAGE network (the station map is shown in the left panel). LYR and TRO in the panels indicate Longyearbyen and Troms $\varnothing$, respectively. 
with the present CME event. In particular, the electric field obtained from the EISCAT UHF radar observations shows quite large enhancements at around 11:00 and 12:00 UT with more than $120 \mathrm{mV} \mathrm{m}^{-1}$ at around 12:00 UT. The quantitative estimates of the heating rates and the resultant enhancements of the ion and neutral temperatures are one of research targets for the future.

As mentioned above, the impacts of a CME arrived at the Earth's ionosphere through the two-step process in the present case. In the first stage, there was strong heating in the higher latitude region (near Longyearbyen) of the polar ionosphere, which was in association with passage of the shock structures of the solar wind. At that time, the polar cap size seemed to be small although the polar cap potential seemed to be large; for example, the Boyle index was calculated to be 88,257 , and $114 \mathrm{kV}$ by using the ACE data at 08:46, 08:56, and 09:06 UT, respectively. In the second stage, there was strong heating in the lower latitude region (to the south of Longyearbyen and north of Troms $\varnothing$ ) of the polar ionosphere, which was in association with the southward IMF- $B_{z}$ component lasting more than $1.5 \mathrm{~h}$ after the passage of the shock structures. The polar cap size seemed to have expanded. The polar cap potential also seemed to be large; the Boyle index was calculated to be more than $200 \mathrm{kV}$ and $175-91 \mathrm{kV}$ by using the ACE data during 10:2611:06 UT and 11:16-11:36 UT, respectively. Figure 10 shows the X-components of the geomagnetic field obtained from the IMAGE magnetometer network observations (http://www. ava.fmi.fi/image/). The IMAGE network covers the geographic/geomagnetic latitude region from $78.92^{\circ} / 75.25^{\circ}$ (Ny Allesund: NAL) to $58.26^{\circ} / 54.47^{\circ}$ (Tartu: TAR). The latitudinal variation of the geomagnetic field suggests the existence of strong currents at higher and lower latitudes in the first and second stages, respectively, as shown in Fig. 10. The spatiotemporal variations of the geomagnetic field are consistent with the ion temperature variations shown in Figs. 5, 7 , and 9. The geomagnetic field variations obtained with the magnetometer could have been caused by the Hall currents, while the Pedersen currents are associated with Joule heating. Since the Hall and Pedersen currents could be related, the magnetometer data should reflect variations of the heating rate and the heating region.

Many researchers have investigated variations of the ionosphere/thermosphere caused by solar wind high-speed streams/CIRs during the declining phase and near the minimum of the solar cycle. For example, Gardner et al. (2012) showed the ion temperature enhancement due to arrival of the solar wind high-speed streams/CIRs from the ESR observations during the period of days 194-201 in 2007. The ion temperature changed from about 820 to more than $1300 \mathrm{~K}$ (rise of about 500-600 K) within about two days. On the other hand, the ESR observed the ion temperature rise of about $2300 \mathrm{~K}$ within about $1.5 \mathrm{~h}$ in the present study, namely, during periods of the CME-induced geomagnetic activity. As mentioned by Chen et al. (2012), the ion temperature rise due to the CME-induced geomagnetic activity was much larger than that due to the CIR-induced geomagnetic activity although the durations of the CME-induced disturbances were much shorter than those of the CIR-induced ones.

As seen in Fig. 7, only Ti-5 showed the sudden excursion and extremely large value at around 12:00 UT although variations of Ti-2 and Ti-5 and variations of Ti-3 and Ti-4 were similar during the period except for around 12:00 UT. This suggests that the scale size of the heating region/heat source could have varied during the event. The CME-induced geomagnetic activity could have caused drastic variations and large amplitudes of disturbances in the polar ionosphere/thermosphere. The impacts of the CME-induced geomagnetic activity on the ionosphere/thermosphere, e.g., generations of strong thermospheric circulation and traveling ionospheric/atmospheric disturbances (TIDs/TADs), will be investigated from general circulation model (GCM) simulations (e.g., Fujiwara and Miyoshi, 2006, 2009) as the next step of the present study.

Acknowledgements. We thank the staff of EISCAT for operating the facilities. EISCAT is an international association supported by research organizations in China (CRIRP), Finland (SA), Japan (NIPR and STEL), Norway (NFR), Sweden (VR), and the United Kingdom (NERC). We thank the ACE SWEPAM instrument team and the ACE Science Center for providing the ACE data. Thanks also to the staff of WDC-C2 for providing the provisional geomagnetic indices. The solar image data obtained from the STEREO observations were provided by the STEREO Science Center/NASA. We thank the institutes who maintain the IMAGE magnetometer array and RSI/Rice University who provided the Boyle index. This work was supported in part by Grant-in-Aid for Scientific Research B (22403010, 23340144, 23340149, 25287126) by the Ministry of Education, Science, Sports and Culture, Japan. A part of this work was also supported by the joint research programs of the SolarTerrestrial Environment Laboratory, Nagoya University and the National Institute of Polar Research, Japan.

Topical Editor K. Hosokawa thanks M. Kosch and one anonymous referee for their help in evaluating this paper.

\section{References}

Boyle, C. B., Reiff, P. H., and Hairston, M. R.: Empirical polar cap potentials, J. Geophys. Res., 102, 111-125, doi:10.1029/96JA01742, 1997.

Carlson, H. C., Spain, T., Aruliah, A., Skjaeveland, A., and Moen, J.: First-principles physics of cusp/polar cap thermospheric disturbances, Geophys. Res. Lett., 39, L19103, doi:10.1029/2012GL053034, 2012.

Chen, G., Xu, J., Wang, W., Lei, J., and Burns, A. G.: A comparison of the effects of CIR- and CME-induced geomagnetic activity on thermospheric densities and spacecraft orbits: Case Studies, J. Geophys. Res., 117, A08315, doi:10.1029/2012JA017782, 2012.

Denton, M. H., Borovsky, J. E., Skoug, R. M., Thomsen, M. F., Lavraud, B., Henderson, M. G., McPherron, R. L., Zhang, J. C., and Liemohn, M. W.: Geomagnetic storms driven by ICME- 
and CIR-dominated solar wind, J. Geophys. Res., 111, A07S07, doi:10.1029/2005JA011436, 2006.

Fujiwara, H. and Miyoshi, Y.: Characteristics of the largescale traveling atmospheric disturbances during geomagnetically quiet and disturbed periods simulated by a whole atmosphere general circulation model, Geophys. Res. Lett., 33, L20108, doi:10.1029/2006GL027103, 2006.

Fujiwara, H. and Miyoshi, Y.: Global structure of large-scale disturbances in the thermosphere produced by effects from the upper and lower regions: simulations by a whole atmosphere GCM, Earth Planets Space, 61, 463-470, 2009.

Fujiwara, H., Kataoka, R., Suzuki, M., Maeda, S., Nozawa, S., Hosokawa, K., Fukunishi, H., Sato, N., and Lester, M.: Electromagnetic energy deposition rate in the polar upper thermosphere derived from the EISCAT Svalbard radar and CUTLASS Finland radar observations, Ann. Geophys., 25, 23932403, doi:10.5194/angeo-25-2393-2007, 2007.

Fujiwara, H., Nozawa, S., Maeda, S., Ogawa, Y., Miyoshi, Y., Jin, H., Shinagawa, H., and Terada, K.: Polar cap ionosphere and thermosphere during the solar minimum period: EISCAT Svalbard radar observations and GCM simulations, Earth Planets Space, 64, 459-465, 2012.

Gardner, L., Sojka, J. J., Schunk, R. W., and Heelis, R.: Changes in thermospheric temperature induced by highspeed solar wind streams, J. Geophys. Res., 117, A12303, doi:10.1029/2012JA017892, 2012.

Kataoka, R. and Miyoshi, Y.: Flux enhancement of radiation belt electrons during geomagnetic storms driven by coronal mass ejections and corotating interaction regions, Space Weather, 4, S09004, doi:10.1029/2005SW000211, 2006.

Kataoka, R., Watari, S., Shimada, N., Shimazu, H., and Marubashi, K.: Downstream structures of interplanetary fast shocks associated with coronal mass ejections, Geophys. Res. Lett., 32, L12103, doi:10.1029/2005GL022777, 2005.
Lei, J., Thayer, J. P., Forbes, J. M., Sutton, E. K., and Nerem, R. S.: Rotating solar coronal holes and periodic modulation of the upper atmosphere, Geophys. Res. Lett., 35, L10109, doi:10.1029/2008GL033875, 2008a.

Lei, J., Thayer, J. P., Forbes, J. M., Wu, Q., She, C., Wan, W., and Wang, W.: Ionosphere response to solar wind high-speed streams, Geophys. Res. Lett., 35, L19105, doi:10.1029/2008GL035208, 2008b.

Lei, J., Thayer, J. P., Wang, W., and McPherron, R. L.: Impact of CIR storms on thermosphere density variability during the solar minimum of 2008, Solar Phys., 274, 427-437, doi:10.1007/s11207-010-9563-y, 2011.

Liu, H., Lühr, H., Henize, V., and Köhler, W.: Global distribution of the thermospheric total mass density derived from CHAMP, J. Geophys. Res., 110, A04301, doi:10.1029/2004JA010741, 2005.

Lühr, H., Rother, M., Köhler, W., Ritter, P., and Grunwaldt, L.: Thermospheric up-welling in the cusp region: Evidence from CHAMP observations, Geophys. Res. Lett., 31, L06805, doi:10.1029/2003GL019314, 2004.

Richardson, I. G., Webb, D. F., Zhang, J., Berdichevsky, D. B., Biesecker, D. A., Kasper, J. C., Kataoka, R., Steinberg, J. T., Thompson, B. J., Wu, C.-C., and Zhukov, A. N.: Major magnetic storms (Dst $\leq-100 \mathrm{nT}$ ) generated by corotating interaction regions, J. Geophys. Res., 111, A07S09, doi:10.1029/2005JA011476, 2006.

Thayer, J. P., Lei, J., Forbes, J. M., Sutton, E. K., and Nerem, R. S.: Thermospheric density oscillations due to periodic solar wind high-speed streams, J. Geophys. Res., 113, A06307, doi:10.1029/2008JA013190, 2008.

Sojka, J. J., McPherron, R. L., van Eyken, A. P., Nicolls, M. J., Heinselman, C. J., and Kelly, J. D.: Observations of ionospheric heating during the passage of solar coronal hole fast streams, Geophys. Res. Lett., 36, L19105, doi:10.1029/2009GL039064, 2009 . 